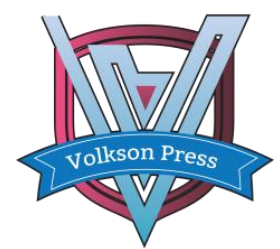

Contents List available at VOLKSON PRESS

Computer Science and Artificial Intelligence(CSAI)

DOI : http://doi.org/10.26480/iscsai.01.2017.09.13

\title{
Analysing Factors Influencing e-Government Development in Zambia: A Principal Component Analysis Approach
}

\author{
Bwalya Kelvin Joseph \\ Department of Information and Knowledge Management, University of Johannesburg, Auckland Park, Johannesburg, South Africa \\ Corresponding Author: kbwalya@uj.ac.za
}

This is an open access article distributed under the Creative Commons Attribution License, which permits unrestricted use, distribution, and reproduction in any medium, provided the original work is properly cited

\section{ARTICLE DETAILS}

\section{Article History:}

Received 02 october 2017 Accepted 06 october 2017 Available online 11 october 2017

Keywords:

e-Government; Principal Component Analysis; Zambia; factor exploration

\section{ABSTRACT}

Effervescent e-Government development entails that e-Government applications and solutions are accessed by a majority of citizens and businesses accessing many of government information or services and participating in the different governance value chains. In the case of Zambian where e-Government development is in its nascent stages, anecdotal evidence suggests that a majority of the population and businesses do not engage in e-Government let alone know that it is being implemented in Zambia. Because of a large number of e-Government projects failing to meet their expectations especially in resource-constrained environments, the need to carefully understand contextual factors influencing e-Government development cannot be overemphasized. This research explores multivariate analysis of factors modelled as multivariate random variables. The study analyses individual factors influencing e-Government using Principal Component Analysis (PCA) as a factor reduction process. The end of PCA shows the critical factors at the centre of e-Government development in Zambia.

\section{Introduction}

It cannot be overemphasized that many countries around the globe have jumped onto the bandwagon of implementing e-Government in their public governance value chains with a view of achieving public service efficiency and innovation. Although some countries have genuine mandates motivating them to implement e-Government given the state of their public administration, some are implementing it to keep up with the Joneses. Despite rolling out its e-Government programme nearly a decade ago, Zambia has nothing much to show for regarding the metamorphosis of its public service delivery away from intermittent corruption, red tape and general inefficiencies. Cases for e-Government's impact on the reduction of corruption are abundant: South Korea's online procedures enhancement for civil applications (OPEN) project and Government eProcurement System (GePS), India's e-Government project assessment, Pakistan's tax department restructuring, the Philippine's e-Procurement system...have all demonstrated massive reductions in the corruption instances (Pathak and Prasad, 2006; Bhatnagar et al., 2007; Iqbal, \& Jin, 2008). Although, e-Government is never a panacea for entrenched problems in public service delivery which are an accumulation of continued negligence of desired public service quality service levels, positive change is expected when it is implemented because it acts as a lever for improved efficiency and effectiveness.

This paper articulates the general outlook of e-Government in Zambia and thereafter presents the empirical results in a bid to understand the factors influencing adoption and usage of e-Government in Zambia. The major assumption in this study is that the individual adoption and usage of eGovernment solutions directly shows the level of development of eGovernment in Zambia. The empirical research generated a large dataset with many uncorrelated predictors which made it very difficult to analyse without a carefully informed statistical approach. Using this data in the analysis at this stage was not possible of many unrelated variables. Most of this data has very little to do with explaining the level of e-Government development in Zambia and had correspondingly low eigenvalues. In order to reduce the number of variables to a small set with correlated variables that could possibly be involved in the analysis, factor analysis using Principal Component Analysis (PCA) was apparent. PCA is a factor reduction procedure that reduces a large dataset with uncorrelated variables to a small set with largely correlated variables where statistical inferences can easily be drawn. At the end of the rigorous statistical procedure, a total of seven (7) variables accounting for maximum variance in the predictor variables were extracted from the dataset.

\section{Background}

E-Government is better understood by first comprehending its key implications (benefits and negative effects). Driven by massive informatisation and infocracy where traditional government processes are replaced by innovative public service delivery facilitated by ICTs, eGovernment shows many forms of positives that need to be explored regardless of the context/environment in which it is implemented (Das, Singh \& Joseph, 2016). The key motivation of using ICTs in the public sector delivery platforms was that e-Government will be a vehicle for streamlining workflows and processes for the integration of data and information into the public service delivery platforms. The desired outcome out of this streamlining was an improvement in the communication channels for effervescent engagement of government organs and individuals/businesses (Machova \& Lnenicka, 2016). EGovernment culminates into the reduction of inefficiencies in the public service business processes, reduces the cost of public services, helps in the mitigation of corruption, etc. (Ndou, 2004, Rokhman, 2011, Cloete, 2012, Dang \& Pekkola, 2017). In many instances where e-Government is implemented for the sake of jumping on the bandwagon, there is usually no careful design of the integration of the technology (ICTs) and the actual public service business processes culminating into misalignment between e-Government technology and organisational processes. This misalignment translates into missing out on many e-Government benefits (Pederson, 2016). Recognising the benefits of e-Government, the government of Indonesia has put in place policies such as the 2003 Presidential Instruction Number 3 that promotes the proliferation of eGovernment at all levels of the economy (Rokhman, 2011).

Despite the many perceived benefits of e-Government as far as public service improvement is concerned, there are also negatives that need to be considered during the design of e-Government applications. Many eGovernment stakeholders have posited that within the ambit of contemporary public service, e-Government is perceived to add more technological and organisational sophistication on the already congested public sector arena given institutional isomorphism and the conflicting interests of politics and pure public management as a public good (GilGarcia \& Ignacio, 2005). Further, there is concern that e-Government projects are not designed to follow unison objectives/agendas and 
development projectiles. For example, in the Kingdom of Jordan, eGovernment is hinged on the agenda for the nation's transformation into a knowledge-based economy driving competitiveness and dynamism in all corners of the economy whereas in India, the focus is to mitigate corruption in the public sector (Dang \& Pekkola, 2017; Fakhouri, 2014). In the case of the Kingdom of Jordan, e-Government in this context is posed to achieve improved government performance and efficiency by streamlining information and public administration processes, enhance overall governance competitiveness, increase transparency and accountability, reduced cost of overall public service delivery, improve skill base and innovation in the public sectors, etc. (Fakhouri, 2014).

When not carefully designed to dovetail into the contextual characteristics of the area in which it is implemented, e-Government shows many negative effects. Some negative implications of e-Government are: unmonitored external linkages on e-Government sites may provide a gateway to minors to restricted content online such an pornographic sites or possible bullying opportunities; comes with huge socio-economic cost as financial resources dedicated to the design and implementation of eGovernment may be used for building social infrastructure such as schools, hospitals, etc.; may translate into citizens' exclusion from the governance and decision-making value chains; may translate into massive retrenchments of public service employees; etc. (Ndou, 2004; Zhan-qi, Xue \& Zhang, 2009). The gravity of the aforementioned negative implications of e-Government may vary given the context in which e-Government is implemented.

Because of a thin line between success or failure of e-Government (Heeks, 2003; Dang \& Pekkola, 2017), efforts to understand factors limiting meaningful development of e-Government in different context setups have in the past decade taken centre stage in e-Government research. The thinking of researchers and practitioners has been that designing innovative ideas, solutions and interventions emanates from adequately understanding the key factors that influence e-Government adoption, usage and the general integration of ICTs into the different public service business processes. Although it cannot be denied that e-Government offers a cornucopia of research domains, research focussing on e-Government design in developing countries is generally in limited supply (Wirtz, Mory, Piehler \& Daiser, 2014). Only a few countries such as South Africa, Mauritius and Seychelles have shown serious interest in researching the different dimensions of e-Government and implementing the lessons. Since 1998, South Africa has been implementing e-Government with formation of a dedicated government department (State Information Technology Agency - SITA) to spearhead integration of ICTs in different government business processes. However, there is paralysis of eGovernment advancement due to structural and operational deficiencies, a leadership hiatus in the designing of requisite policies to support responsive e-Government, lack of monitoring and evaluation of eGovernment activities, etc. Therefore, e-Government in South Africa has not changed substantially given the changing environment and stakeholders' preferences (Cloete, 2012).

Many e-Government initiatives have either focussed on the supply or demand side of e-Government but not on both. There are very few studies that have attempted to integrate studies from the two extremes. Therefore, there is a general lack of adequate understanding in the relationships that exist between the technological dimensions and the different social structures in different places (Elsheikh \& Azzeh, 2014). One of the very steps in the designing dynamic e-Government solutions is to understand the kind of adaptive ICT and management infrastructures needed to support the desired e-Government applications. Prior to designing any e-Government solutions, in-depth studies need to be conducted to understand what types or aspects of ICT infrastructure will facilitate faster e-Government growth and adapt to the changing contextual changes over time. Understanding what ICT infrastructure is needed right at the beginning of e-Government design is important because it informs the designers where they need to allocate their resources (Das, Singh \& Joseph, 2016). Although still lacking, other eGovernment enthusiasts have focused on enterprise architecture (EA) investigations and the broader spectrum of EA investigation other than mere case studies of e-Government (Dang \& Pekkola, 2017). Yet others have focussed on business process re-engineering of e-Government applications (Alghamdi, Goodwin \& Rampersad, 2014).

\section{Theoretical Grounding}

The Principal Component Analysis (PCA), closely related to the KarhunenLoeve transform (KLT), is used in the analysis of multidimensional dataset so as extract factors contributing maximum variance to the adoption and usage of e-Government. The use of PCA is commensurate to the analysis of the multidimensional aspects of e-Government. As early as 1904, Pearson had started investigating PCA as a data reduction technique in contexts where a large dataset needs to be analysed with large number of uncorrelated variables. The PCA uses dimension reduction or 'data reduction' techniques which are methods used to reduce the number of variables explaining variance in a given scenario. Further, PCA uses linear transformations of data to retain fewer factors which maximally explains the variance in a phenomenon. PCA may further be looked at as a noisereduction procession where data which contributes to attenuation of the value of data are removed.

PCA can be used to present data in one-dimensional space which can then easily be analysed. In contemporary data and computational sciences, PCA can be used in creatig algorithms and tools for use in big data analytics, data clustering, pattern recognition, data or classification applications, etc., and can therefore be seen as a backbone to contemporary data analysis domains. Specifically, PCA allows the generation of new sets of data from a huge dataset with linear combinations of variables uncorrelated with each other and ordered according to the degree of explanation of variance in the original variables (Everitt \& Hothorn, 2011). Although PCA has many advantages, it also comes with a higher computational cost compared to other potential methods that can be used in data reduction such as the Fourier Transform.

PCA is founded upon applied linear algebra and non-parametric methods forming a mathematical conceptualisation used for extracting relevant data from complex data sets. The mathematical procedure for the PCA starts from the data dimensionality reduction procedure where only variables showing promise are extracted. Principal Components are a linear combination of optimally-weighted variables. PCA is then done by shifting dataset in a coordinate system using the data vectors with greatest modes of variance. The data used in this research has a large number of variables and therefore it was important that PCA be used to reduce redundancy so that it can be prepared for further analysis. Redundancy in the variables can occur because some of the variables are correlated because they are measuring the same construct. The key assumption in the use of PCA is that the reduced number of variables will account for most of the variance in the predictor variables. The independent variables are referred to as predictors and the dependent variables are the criterionvariables. Each of the variables is analysed independently using one-way ANOVA bivariate analysis to gain statistical inferences and at the end of the analysis a combined multivariate procedure is utilised to analyse the combined effect on the overall adoption and use of e-Government of the individual variables simultaneously. The use of multivariate descriptive statistics enabled the researcher to investigate the dataset as the entire population of interest and finally obtaining multivariate descriptives such as $\mathrm{R}^{2}$ as a final measure of variance.

The PCA procedure follows distinct sets of steps to ensure that only the factors with higher communalities are included in the final set of factors accounting for the highest variance in the predictor variables. After the empirical study with $\mathrm{N}$ observations, a dataset was obtained with $\mathrm{X}$ variables (dimensions) which represents the multidimensionality in the dataset represented by the equation below as a set of data column vectors which are artificial variables (Principal Components):

$$
Y_{1}=\mu_{11} X_{1}+\mu_{12} X_{2}+\mu_{13} X_{3}+\cdots+\mu_{1 p} X_{p}
$$

The coefficients $\mu_{i N}$ will be different for each off the different datasets Equation [1] can further be represented in a matrix form of size [M by $N$ ] using the Euclidean product as

$$
Y_{1}=\mu_{1}^{T} X
$$

The aim is to reduce the dimensionality of the dataset by rotating it around the XYZ coordinate plane. PCA is applied to the normalised data by first obtaining the empirical mean as

$$
\zeta=\frac{1}{N} \sum_{n=1}^{N} R(m, n)
$$

where $m=1 \ldots . . M$.

The emprical mean is then subtracted from each column of R. Given that $\epsilon$ is a unit vector of size $\mathrm{N}$, we can thus posit $X=R-u \epsilon$. Approximating $\mathrm{X}$ in a lower dimensional plane $\mathrm{M}$ of the given matrix $Y_{i}$ (of dimension $\mathrm{Z}$ ), the mean square error can be approximated as follows:

$\varepsilon^{2}=\frac{1}{N} \sum_{n=1}^{N}\left|X_{n}\right|^{2}-\sum_{i=1}^{Z} b_{i}^{T}\left(\frac{1}{N} X_{n} X_{n}^{T}\right) b_{i}$ 
We can minimise $\varepsilon^{2}$ using a symmetric, positive semi-definitive covariance matrix as follows:

$$
\left.\varepsilon^{2}=\sum_{i=1}^{Z} b_{i}^{T} \operatorname{cov}(x) b_{i}, \text { where } \operatorname{cov}(x)=\sum_{n=1}^{N} X_{n} X_{n}^{T}\right)
$$

Each of the Principal Components is obtained by maximising $v^{T} \sum v$ so that the end result obtains $v^{T} v=1$. Using the Lagrange multipliers with $\Lambda(v)=v^{T} \sum v+\Lambda\left(1-v^{T} v\right)$ and taking a derivative with respect to $v$ and equating the equation to zero as espoused in the Lagrange energy conservation equation,

$\frac{\partial \Lambda(v)}{\partial v}=2 \sum v-2 \lambda v=0$ [Lagrange optimization problem $]$

we can therefore posit that the following equation holds:

$$
\sum v=\lambda v
$$

where $v$ is the eigenvector of the covariance matrix which corresponds to the maximum variance from the covariance matrix $(\Sigma)$ corresponding to the eigenvalue $\lambda$.

The conceptualisation of the eigenvalue problem can be conceptualized as follows: Given the eigenvalue problem with $A . v=\lambda . v$ where A is a ' $m$ ' by ' $\mathrm{p}$ ' matrix, $v$ is a ' $\mathrm{m}$ ' by ' 1 ' non-zero vector and $\lambda$ is a scalar. Therefore, any value of $\lambda$ which ensures that the equation above has a solution is known as the eigenvalue of $A$ and the vector corresponding to this value is called the eigenvector of A. By shifting the directions of the rotations on the Euclidean plane, we were able to obtain successive Principal Components with projected maximum variance. In this study, the obtained factors explaining e-Government adoption in Zambia represent the Principal Components as $\mathrm{K}$ eigenvalues with largest eigenvalues from the data covariance matrix representing the likelihood of factors that can explain many of the variance in the predictor variable. The value of the eigenvectors determines the Component Factors to be included in the final analysis from the dataset.

\section{Research Approach}

The research's conceptual framework was hinged on the TAM, TAM2 and UTAUT only including constructs that are logically relevant to the contextual setting in which this research was conducted. Each of the constructs in the conceptual framework had a set of questions which were included into the data collection instruments (questionnaire with closed and open-ended questions, and interviews). Out of the 721 questionnaires distributed, only 411 were returned and 408 were finally included in the analysis of the data. The participants were included in the study based on purposive and snowball sampling.

The research uses methodological triangulation at all stages of the research cycle so as to interrogate same phenomenon from different vantage points. Multiple regression was used to explore the relationship between one continuous dependent variable and a number of independent variables or predictors.

In order for the dataset to pass desired reliability and validity and to conform to established statistical assumptions for inferential statistics in the multivariate analysis, it was apparent that it be subjected to preliminary tests. The first statistical assumption is that the dataset needs to follow the Gaussian normal distribution. A further assumption is that multivariate normality is achieved if all of the bivariate data in the dataset follows a normal distribution curve as tested using the KolmogorovSmirnov and the Shapiro-Wilk test. Therefore, each of the bivariate data was subjected to normality testing. The preliminary tests showed that the data was negatively skewed confirming the presence of outliers which could distort the regression coefficients. The data in figure 1 below shows negative skewness with a clear case of an outlier. Therefore, the data does not follow normality. The same data was plotted using a boxplot also presenting the same case where the outlier and the negative skewness is clearly identifiable. Therefore, the data was transformed using a logarithmic function $\log _{10}(6-x)$ to remove the negative skewness. After transformation, the data followed normality.
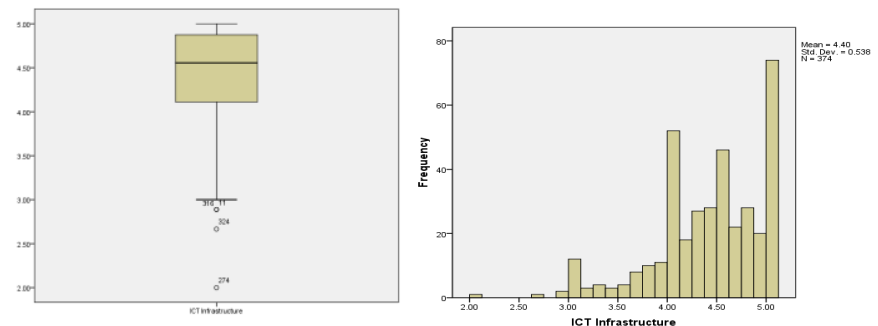

Figure 1. Histogram and boxplot on 'ICT infrastructure' dataset

KMO Measure of Sampling Adequacy tests whether an adequate sample was used in the empirical part of the study. The KMO test in this study shows $\chi 2(66)=2701.097, p<0.001$ (level of significance at 0.005 ) with a value of 0.919 showing that more than an adequate sample was used in the study as shown in Table 1.

\begin{tabular}{|c|c|c|}
\hline \multicolumn{2}{|c|}{ Kaiser-Meyer-Olkin Measure of Sampling Adequacy. } & .919 \\
\hline \multirow[t]{3}{*}{ Bartlett's Test of Sphericity } & Approx. Chi-Square & 2701.097 \\
\hline & Df & 66 \\
\hline & Sig. & .000 \\
\hline
\end{tabular}

Table 1. KMO and Bartlett's Test

After the preliminary tests, the observed data is first coded and presented in a matrix format [with dimensions $[\mathrm{m} \mathrm{x} \mathrm{p]}$. From this matrix, Correlation Matrix $(\Sigma)$ was calculated and the corresponding Covariance Matrix. Given the two matrices obtained, it is now possible to calculate the eigenvalues and eigenvectors. From there, we generated the proportion of total variation explained by the $\mathrm{j}^{\text {th }}$ Principal Component. Finally, you choose the number of Principal Components, and generating plots to explain the results of the analysis. Because this study uses data with many measurement items and therefore difficult to easily discern the many inherent associations among the data, it was difficult to understand which factors account for adoption of e-Government in Zambia without a careful statistical analysis. Therefore, factor or dimensional reduction to consider only factors with large variance was apparent. The value of the eigenvectors determines the Component Factors to be included in the final analysis from the dataset.

The study uses restricted Exploratory Factor Analysis (EFA) at 0.005 level of significance. The EFA is done in conjunction with Principal Component Analysis (PCA) employing principal axis factoring as factor extracting methodology. The oblique rotation methodology used in PCA factor optimisation is Promax with Kaiser Normalisation. After initial factor solution was obtained, it was important to manipulate the factor axes in the Factor Matrix to achieve a more acceptable factor solution. Instead of orthogonal (90 degree) solution, the factors were rotated in such a way that the factors extracted were more correlated. We then computed the factor/component loadings obtaining PCA coefficients between variables (shown in the rows) and factors (shown in the columns) as shown in the Factor Matrix in Appendix 1 below in the initial factor solution. The PCA procedure done in conjunction with restricted exploratory factor analysis was performed on the dataset as follows:

1. First round of analysis, 15 factors were extracted after 13 iterations of principal axis factoring as the extraction method.

2. In the second round, two cases with low communalities $(<0.3)$ were excluded, with rotations converging after 19 iterations using promax and Kaiser normalisation culminating into 9 factors being extracted.

3. The last round saw seven factors extracted. Extraction communalities depict the estimates of variance in each variable accounted for by a given factor.

The statistical procedures show the total variance explained by the factors extracted after rotation as shown in figure 2. Although all the 14 factors extracted are able to explain $100 \%$ variance, only seven factors (explain 54\% variance) are included in analysis due to differences that may arise from individual orientations.

\begin{tabular}{|c|c|c|c|c|c|c|c|c|}
\hline \multirow[t]{2}{*}{ Factor } & & \multicolumn{3}{|c|}{ Initial Eigenvalues } & \multicolumn{3}{|c|}{$\begin{array}{l}\text { Extraction Sums of Squared } \\
\text { Loadings }\end{array}$} & \multirow{2}{*}{\begin{tabular}{|l|}
$\begin{array}{l}\text { Rotation Sums of } \\
\text { Squared } \\
\text { Loadings }\end{array}$ \\
Total \\
\end{tabular}} \\
\hline & & Total & $\begin{array}{l}\% \text { of } \\
\text { Variance }\end{array}$ & $\begin{array}{l}\text { Cumulative } \\
\%\end{array}$ & Total & $\begin{array}{l}\text { \% of } \\
\text { Variance }\end{array}$ & $\begin{array}{l}\text { Cumulative } \\
\%\end{array}$ & \\
\hline \multirow{14}{*}{ dimension0 } & 1 & 13.642 & 20.061 & 20.061 & 13.195 & 19.404 & 19.404 & 10.197 \\
\hline & 2 & 7.268 & 10.688 & 30.749 & 6.819 & 10.028 & 29.432 & 8.475 \\
\hline & 3 & 5.339 & 7.851 & 38.600 & 4.878 & 7.173 & 36.605 & 5.841 \\
\hline & 4 & 3.301 & 4.855 & 43.455 & 2.848 & 4.188 & 40.793 & 7.252 \\
\hline & 5 & 2.881 & 4.237 & 47.691 & 2.473 & 3.637 & 44.430 & 7.945 \\
\hline & 6 & 2.731 & 4.017 & 51.708 & 2.321 & 3.413 & 47.843 & 4.938 \\
\hline & 7 & 1.836 & 2.700 & 54.408 & 1.373 & 2.019 & 49.862 & 3.972 \\
\hline & 8 & 1.781 & 2.619 & 57.027 & 1.357 & 1.996 & 51.858 & 2.858 \\
\hline & 9 & 1.743 & 2.563 & 59.590 & 1.290 & 1.897 & 53.754 & 2.302 \\
\hline & 10 & 1.357 & 1.996 & 61.586 & & & & \\
\hline & 11 & 1.303 & 1.916 & 63.502 & & & & \\
\hline & 12 & 1.277 & 1.878 & 65.380 & & & & \\
\hline & 13 & 1.038 & 1.526 & 66.906 & & & & \\
\hline & 14 & 1.004 & 1.477 & 68.383 & & & & \\
\hline
\end{tabular}

Table 2. Total Variance Explained 
Only factors with higher communalities after rotation were included in the analysis. Each of the factors extracted were further subjected to normality testing using the Kolmogorov-Smirnov and Shapiro-Wilk tests as shown in Table 3.

Table 3. Tests for Normality on all measured items

\begin{tabular}{|l|l|l|l|l|l|l|}
\hline \multirow{2}{*}{} & \multicolumn{3}{|l|}{ Kolmogorov-Smirnova } & \multicolumn{2}{l|}{ Shapiro-Wilk } \\
\cline { 2 - 7 } & Statistic & df & Sig. & Statistic & Df & Sig. \\
\hline ICT_infra ICT Infrastructure & .132 & 374 & .000 & .901 & 374 & .000 \\
PEOU & .142 & 377 & .000 & .972 & 377 & .000 \\
PU & .117 & 401 & .000 & .930 & 401 & .000 \\
Comp_SE & .178 & 405 & .000 & .880 & 405 & .000 \\
Facilitating conditions & .129 & 405 & .000 & .899 & 405 & .000 \\
Trust & .149 & 377 & .000 & .951 & 377 & .000 \\
Social Influence & .147 & 374 & .000 & .924 & 374 & .000 \\
\hline
\end{tabular}

The results of normality testing and linearity can be shown in figure 2 . The residual statistics shown below in Figure 2 confirmed that the Mahalanobis distance has an acceptable value and the P-P plot for standardised residue shows linearity in the dataset.
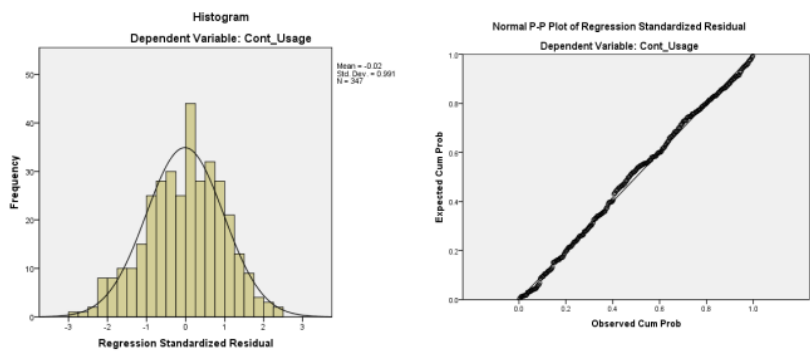

Figure 2. (a) Gaussian normal data fit of $\mathrm{CU}$ on all other variables

(b) P-P plot for standardised residue of $\mathrm{CU}$ on all other variables

The seven factors can now be used to obtain statistical inferences with regards to the development of e-Government in Zambia.

\section{Discussions}

In order to obtain a general understanding of the status of e-Government development in Zambia, the descriptive statistics obtained from the study revealed that:

1) The majority of the respondents have the requisite ICT skills to effectively engage in e-Government although the actual usage of eGovernment applications is low as only $27 \%$ of the respondents indicated having ever used e-Government applications;

2) $49 \%$ of the people surveyed indicated that they were not aware of eGovernment being implemented in Zambia, with 30\% being moderately aware of available e-Government services. This points to the fact that there are not enough e-Government awareness campaigns being implemented in Zambia;

3) $61 \%$ of the respondents indicated that most e-Government websites or platforms are not reliable and that they cannot generally trust eGovernment platforms with $84 \%$ pointing out lack of security policies and a further $84 \%$ of the respondents they would not be comfortable in sharing their personal information with government platforms; and

4) Over $50 \%$ of respondents are in agreement that under-developed ICT infrastructure in Zambia is negatively impacting on e-Government development.

The factors extracted using PCA confirm these sentiments from the descriptive statistics. Further, the factors extracted have shown that generally Zambia does not have requisite ICT infrastructure to support dynamic e-Government applications. The limited ICT infrastructure is concentrated along the line of rail with the cities of Livingstone, Lusaka and Kitwe having the largest share. The international gateway is still managed by Zamtel, a state telecommunication enterprise, making access to the Internet expensive and ultimately reducing any meaningful chances for e-Government development. Many of the people surveyed indicated that they have limited skills - indicating the need for ICT education to up the ICT skills of the citizens and computer self-efficacy. Social influences and facilitating conditions was also found to contribute to influencing actual system usage of the system. If an e-Government Champion were to be appointed to coordinate and motivate the integration of ICTs at a global level in the public sector, many government employees would be prompted to use technology in delivering public services. Supporting or conducive environment and incentives have to be put in place in order to facilitate desired e-Government growth.

\section{Conclusions and Limitations}

This study probed the factors that influence e-Government development by probing the individuals' perceptions and knowledge of e-Government implementation in Zambia. PCA was used to guide the statistical analysis of the data obtained using questionnaires, document reviews and interviews. The study used a conceptual framework hinged upon TAM, TAM2 and UTAUT. The results of the study show that e-Government implementation in Zambia is still at the nascent stage and therefore a lot of interventions needs to be put in place if technology stand a chance of being used at a global scale in everyday public service business processes. The factors identified can be used as pointers in guiding interventions aimed at accelerating e-Government implementation in Zambia. The study major limitations are: 1) Does not measure actual participants' behaviour but measures 'behaviour intention' although perceived to have a direct causative relationship on technology adoption and utilisation (as posited by Vekantesh et al., 2003); and 2) The sample is limited and confined to the major cities along the line of rail in Zambia - may not be as representative of the whole population in Zambia. Therefore, the statistical inferences obtained in this study need to be used for references purposes only. Further, purposive and snowball sampling used in the study may have implications for the findings generalisability.

\section{Acknowledgements}

This research was part of a PhD project which was self-funded. Special thanks go to the colleagues at STATCON, University of Johannesburg, for providing a statistical eye and ensured that the statistics needed for this study were obtained with ease.

\section{References}

Alghandi, I.A., Goodwin, R., \& Rampersad, G. (2014). Organizational EGovernment Readiness: An Investigation in Saudi Arabia, International Journal of Business and Management, 9(5), 14-24.

Bhatnagar, S.C., Rao, T.P., Singh, N., Vaidya, R., \& Mandal, M. (2007). Impact Assessment study of e-Government projects in India. Center for eGovernance, Indian Institute of Management, Ahmedabad. Available from http://www.iimahd.ernet.in/egov/documents/impact-assessmentstudy-dit.pdf. (Accessed 3 July 2017).

Cloete, F. (2012). Seven: e-government lessons from South Africa 2001 2011: institutions, state of progress and measurement, The African Journal of Information and Communication, 12, 128 -146.

Dang, D., \& Pekkola, S. (2017). Systematic Literature Review on Enterprise Architecture in the Public Sector, The Electronic Journal of e-Government, $15(2), 132-154$

Das, A., Singh. H., \& Joseph, D. (2016). A longitudinal study of e-government maturity, Information and Management http://dx.doi.org/10.1016/j.im.2016.09.006

Everitt, B., \& Hothorn, T. (2011). An introduction to applied multivariate analysis with R. Springer, eBook. ISBN 978-1-4419-9650-3

Fakhouri, S.N. (2014). E-government Adoption and Trends in the Hashemite Kingdom of Jordan, International Journal of Computing Academic Research (IJCAR), 3(4), 89 - 97.

Gil-Garcia, J. R., \& Ignacio J. M.M. (2005). "Exploring E-Government Evolution: The Influence of Systems of Rules on Organizational Action". National Centre for Digital Government Working Paper Series. 18. Online: http://scholarworks.umass.edu/cgi/viewcontent.cgi?article=1016\&cont ext=ncdg

Heeks, R. 2003. Achieving Success/Avoiding Failure in e-Government Projects, IDPM, University of Manchester. Available from http://www.egov4dev.org/success/sfdefinitions.shtml. (Accessed 6 June 2009). 
Iqbal, M. S., \& Seo, J.W. (2008). E-Governance as an Anti-Corruption Tool: Korean Cases, Journal of Korean Association for Regional Information Society, 11(2), 51-78.

Elsheikh Y., \& Azzeh, M. (2014). What Facilitates the Delivery of CitizenCentric EGovernment Services in Developing Countries: Model Development and Validation Through Structural Equation Modeling, International Journal of Computer Science \& Information Technology (IJCSIT), 6(1), 77-98.

Machova, R., \& Lnenicka, M. (2016).Modelling E-Government Development through the Years Using Cluster Analysis, JeDEM 8(1), 62-83

Ndou, V.D. (2004). E-Government for developing countries: opportunities and challenges, The Electronic Journal on Information Systems in Developing Countries (EJISDC), 18(1), 1-24.

Pathak, R. D., \& Prasad, R. S. (2006). Role of E-governance in tackling corruption: The Indian Experience. In Raza Ahmad (Ed.), the role of public administration in building a harmonious society. 434-463. Philippines: Asian Development Bank.

Rokhman, A. (2011). E-Government Adoption in Developing Countries; the Case of Indonesia, Journal of Emerging Trends in Computing and Information Sciences, 228 - 236

Venkatesh, V., Moris, M.G., \& Davis, G.B. (2003). User acceptance of information technology: Toward a unified view, MIS Quarterly, 27(3), 425478.
Wirtz, B.W., Mory, L., Piehler, R., \& Daiser, P. (2014). Measuring egovernment portal management on the local level: results from a survey of public administration officials, International Public Management Review, 15(2), 1-31.

Zhan-qi, D., Xue, Y-W., \& Zhang, P-Z. (2009). An Analysis on the Negative Effects of E-Government Information Opening: Case Study of Coal Administrative Information Opening in Shanxi Province, icic, 1: 289-292, 2009 Second International Conference on Information and Computing Science.

\section{About the Author}

Prof KJ Bwalya has a keen interest in Knowledge Management Systems especially in developing world contexts. He also generally conducts research in the application of information systems in public sector organisations. He has a PhD in Information Management (University of Johannesburg), Masters of Computer Science (Korea Advanced Institute of Science and Technology) and Bachelors in Electrical Electronics Engineering / (Moscow PE Technical University). Recently, he convened a multi-disciplinary international conference in Zambia. He is a postgraduate supervisor and Exam Board member at various universities around the world and member of various professional bodies and editorial teams. He has supervised $5 \mathrm{PhDs}$ to completion, several Masters and undergraduate projects. Published 7 books and over 100 pieces of peer reviewed articles and has also managed numerous research funds. Current research interests are big data, knowledge management, predictive analytics, genomics, information data modelling, etc. 